\title{
Comparative Enhancement of Mild Steel Weld Mechanical Properties for Better Performance Using COPRAS-ARAS Method
}

\author{
S. Nweze and J. Achebo
}

\begin{abstract}
Some machine part failures have often occurred in areas of components where the strength was lowest, especially at its weld region. Presence of voids in weldments or weld joints greatly reduces the quality of the weldment. To prevent these defects, a proper optimum selection of process parameters is highly encouraged to achieve an acceptable weld mechanical property. The Complex Proportional Assessment (COPRAS) method was applied to determine the relative significance of each alternative and the quantitative utility for each alternative. The Addition Ratio Assessment (ARAS) method was applied to optimize these parameters by utilizing the weights generated using COPRAS method. In this study, the COPRAS-ARAS method which is a multi-criteria decision making tools was applied to determine the optimum process parameters to improve the mechanical properties of the weldment. From applying these methods, it was found that weldments 7 , possess the optimum input process parameters. The corresponding mechanical properties of ultimate tensile strength (UTS) of $395 \mathrm{MPa}$, absorbed impact strength (CVN) of $250 \mathrm{~J}$, Bead height (BH) of $1.98 \mathrm{~mm}$ and Bead width (BW) of $4.82 \mathrm{~mm}$ was found to possess the best mechanical properties.
\end{abstract}

Index Terms - Bead height (BH), COPRAS, ARAS, bead width (BW), mild steel, weldment.

\section{INTRODUCTION}

In different parts of Nigeria, there have been the incessant collapse of metal materials, some of which are reported and so many are not reported. In most cases, some of these failures are castatrophic and human lives are lost, or the injury sustained could lead to permanent disability [1]. Most of these failures results from poor weldment leading to compromised UTS, CVN, BH and BW which is very critical in achieving good weld. Researchers has proven that weld input parameters have a very strong effect on the responses [2].

To improve UTS, CVN, BH and BW, it is imperative that the optimum input parameters should be achieved, this can be through experimental means either by trial and error or modelling. The trial and error method takes time and mental energy but modelling that leads to optimization process takes seconds and are usually very precise. There are some authors that have worked on the optimization, [3] worked on air conditioner selection problem with COPRAS and ARAS methods. [4] evaluated some contractors using COPRAS, [5] to reduced greenhouse gas emissions in grassland ecosystems

Submitted on November 04, 2020.

Published on February 12, 2021.

S. Nweze, Department of Production Engineering, University of Benin, Benin City, Nigeria.

(e-mail: stephcherish@gmail.com) off the central Lithuania using ARAS method.

This study uses the application of COPRAS - ARAS method to select the optimum process parameters, since it has been confirmed by researchers that selecting the appropriate input process parameters could lead to improving the welded joint quality.

In this study, the optimization of mechanical properties was looked into. The optimization was done using complex proportional assessment (COPRAS) and Addition Ratio Assessment (ARAS). It has been researched that what influences weldments quality is the welding input parameters.

\section{MATERIALS AND METHODS}

\section{A. Materials}

Tungsten Inert Gas (TIG) machine was used to weld the samples, producing eight experimental runs, each experimental run comprising the current, voltage and gas flow rate, used to join two pieces of mild steel plates measuring $60 \mathrm{~mm} \times 40 \mathrm{~mm} \times 10 \mathrm{~mm}$. The ultimate tensile strength (UTS), absorbed impact strength (CVN), Bead height $(\mathrm{BH})$ and Bead width $(\mathrm{BW})$ were measured respectively. The welding process parameters for the eight (8) samples are shown in Table I.

\begin{tabular}{cccc}
\multicolumn{4}{c}{ TABLE I: WELD PROCESS PARAMETERS } \\
\hline \multicolumn{4}{c}{ Input Parameters } \\
$\begin{array}{c}\text { Weldment } \\
\text { Number }\end{array}$ & $\begin{array}{c}\text { Current, } \\
\text { I }\end{array}$ & $\begin{array}{c}\text { Voltage, } \\
\text { V }\end{array}$ & $\begin{array}{c}\text { Gas Flow } \\
\text { Rate, } \\
\text { GFR (l/min) }\end{array}$ \\
\hline 1 & 140 & 18 & 13 \\
2 & 140 & 18 & 18 \\
3 & 180 & 23 & 13 \\
4 & 180 & 23 & 18 \\
5 & 140 & 23 & 13 \\
6 & 140 & 23 & 18 \\
7 & 180 & 18 & 13 \\
8 & 180 & 18 & 18 \\
\hline
\end{tabular}

\section{B. Methods}

The following steps are applied for the COPRAS method as outlined by [3]. Firstly, it is assumed that there are $\mathrm{m}$ alternatives and $\mathrm{n}$ criteria in the problem [6]:

Step 1: The normalized decision matrix is acquired with linear normalization procedure using Eq. (1) [7].

J. Achebo, Department of Production Engineering, University of Benin, Benin City, Nigeria.

(e-mail: josephachebo@ ${ }^{@}$ yahoo.co.uk) 
$r_{i j}=\frac{x_{i j}}{\sum_{i=1}^{m} x_{i j}} \quad(i=1,2, \ldots m ; \quad j=1,2, \ldots, n)$

where $x_{i j}$ and $r_{i j}$ are the performance of the $i^{\text {th }}$ alternative with respect to the $j^{\text {th }}$ criterion and its normalized value respectively. The values of the criteria with having different units of measurement should be normalized in order to compare them [7].

Step 2: Normalized decision making matrix (D) is weighted as:

$D=\left[d_{i j}\right]_{m x n}=r_{i j} w_{j}$

where $w_{j}$ is the importance weight of $j$ th criterion. Importance weights of criteria may be derived from different weighting methods. In this paper the AHP (Analytic Hierarchy Process) method is used because of its simplicity. It was developed by [8] and it depends on pairwise comparison of criteria More detailed information about the procedure of the AHP method is to be found in the paper of [8].

Step 3: The weighted normalized values are summed for both beneficial and non-beneficial criteria.

$$
\begin{aligned}
& S_{+1}=\sum_{j=1}^{n} d_{+i j} \\
& S_{-1}=\sum_{j=1}^{n} d_{-i j}
\end{aligned}
$$

$d_{+i j}$ and $d_{-i j}$ in Eq. (3) and (4) are the weighted normalized values for the beneficial and non-beneficial criteria respectively. The greater the value of $S_{+i}$, the better is the alternative and the lower the value of $S_{-i}$, the better is the alternative. The $S_{+i}$ and $S_{-i}$ values express the degree of goals attained by each alternative. In any case the sums of $S_{+i}$ and the sums of $S_{-i}$ are equal to the weighted sums for the beneficial and non-beneficial criteria as expressed by equation (5) and (6).

$$
\begin{aligned}
\sum_{i=1}^{m} S_{+i} & =\sum_{i=1}^{m} \sum_{j=1}^{n} d_{+i j} \\
\sum_{i=1}^{m} S_{-i} & =\sum_{i=1}^{m} \sum_{j=1}^{n} d_{-i j}
\end{aligned}
$$

Step 4: The relative significances or priorities of each alternative (Q) are determined using Eq. (7).

$$
Q_{i}=S_{+i}+\frac{S_{-\min } \sum_{i=1}^{m} S_{-i}}{S_{-i} \sum^{m}\left(S_{-\min } / S_{-i}\right)}=S_{+i}+\frac{\sum_{i=1}^{m} S_{-i}}{S_{-i} \sum^{m}\left(1 / S_{-i}\right)} \text { (7) }
$$

where $S_{- \text {min }}$, is the minimum value of $S_{-1}$. The relative significance value of an alternative shows the degree of satisfaction attained by that alternative. The greater the value of $Q_{i}$, the higher is the priority of the alternative. The alternative with the highest relative significance value $\left(Q_{\max }\right)$ is the best choice among the alternatives.

Step 5: The quantitative utility for each alternative $\left(U_{i}\right)$ is calculated. The degree of an alternative's utility which leads to a complete ranking of the alternatives is determined by comparing the priorities of all the alternatives with the most efficient one and can be denoted as presented in Eq. (8).

$$
U_{i}=\left[\frac{Q_{i}}{Q_{\max }}\right] .100 \%
$$

where $Q_{\max }$ is the maximum relative significance value. These utility values of the alternatives range from $0 \%$ to 100 $\%$.

ARAS method consists of the steps as below [3].

Step 1: The decision matrix $X$ in Eq. (9) is formed from Alternatives and criteria that are listed in the row and column of the decision matrix respectively. The decision matrix shows the performance of different alternatives with respect to various criteria.

$X=\left[x_{i j}\right]_{m \times n}=\left[\begin{array}{cccc}x_{11} & x_{12} & \ldots & x_{1 n} \\ x_{21} & x_{22} & \ldots & x_{2 n} \\ \vdots & \vdots & \ddots & \vdots \\ x_{m 1} & x_{m 2} & \ldots & x_{m n}\end{array}\right]$

$(i=1,2, \ldots m ; j=1,2, \ldots, n)$

$x_{i j j}$ presents the performance value of $i t h$ alternative on $j t h$ criterion, $m$ and $n$ are the numbers of alternatives and criteria respectively. Then the optimal performance rating of $j t h$ criterion $\left(x_{0 j}\right)$ is determined. If $x_{0 j}$ is unknown, then it is assumed as the maximum values of beneficial criteria or minimum values of non-beneficial criteria [9].

Step 2: The decision matrix is normalized. Beneficial criteria are normalized with linear normalization procedure as given in Eq. (10).

$x_{i j}^{*}=\frac{x_{i j}}{\sum_{i=1}^{m} x_{i j}}$

where $x_{i j}^{*}$ is the normalized value.

Non-beneficial criteria are normalized with two-stage procedure. In the first stage the reciprocal of each criterion with respect to all the alternatives is taken as given in Eq. (11).

$x_{i j}^{*}=\frac{1}{x_{i j}}$

In the second stage, the normalized values are calculated using Eq. (12).

$R=\left[r_{i j}\right]_{m x n}=\frac{x_{i j}^{*}}{\sum_{i=1}^{m} x_{i j}^{*}}$

Step 3: The normalized decision matrix is weighted using 
Eq. (13).

$D=\left[d_{i j}\right]_{m x n}=r_{i j} \cdot w_{j}$

where $w_{j}$ is the weight (importance) of $j$ th criterion.

Step 4: The optimality function (S1) is determined for each alternative using (14).

$S_{i}=\sum_{j=1}^{n} d_{i j} \quad(i=0,1,2, \ldots m ; j=1,2, \ldots n)$

The highest and lowest $S_{i}$ values are the best and the worst respectively. The optimality function $S_{i}$, has a direct and proportional relationship with the values in the decision matrix and criteria weights. $S_{0}$ is the optimality function of the optimal alternative.

Step 5: The degree of the utility $\left(\mathrm{U}_{\mathrm{i}}\right)$ is determined for each alternative. It is calculated using Eq. (15):

$U_{i}=\frac{S_{i}}{S_{0}}$

In this method, a utility function value determines the relative efficiency of an alternative over the best alternative [6]. The U, values of alternatives range from $0 \%$ to $100 \%$ and they are placed in ascending order. The alternative with the highest utility value is the best choice among the alternatives [9].

\section{RESULTS AND DISCUSSION}

\section{A. Presentation of Results}

Table II shows the measured mechanical properties for the eight (8) samples, ultimate tensile strength (UTS), absorbed impact energy $(\mathrm{CVN})$, Bead height $(\mathrm{BH})$ and Bead width (BW) with their corresponding weights.

TABLE II: MEAsured MechaniCAL PRoperties

\begin{tabular}{|c|c|c|c|c|}
\hline \multirow{3}{*}{$\begin{array}{l}\text { Weldment } \\
\text { W }\end{array}$} & \multicolumn{4}{|c|}{ Mechanical properties } \\
\hline & \multicolumn{2}{|c|}{ Maximum } & \multicolumn{2}{|c|}{ Minimum } \\
\hline & $\begin{array}{l}\text { UTS } \\
(\mathrm{MPa})\end{array}$ & CVN (J) & $\begin{array}{c}\mathrm{BH} \\
(\mathrm{mm})\end{array}$ & $\begin{array}{l}\mathrm{BW} \\
(\mathrm{mm})\end{array}$ \\
\hline 1 & 340 & 210 & 2.62 & 5.00 \\
\hline 2 & 270 & 190 & 2.45 & 9.74 \\
\hline 3 & 330 & 150 & 3.10 & 10.34 \\
\hline 4 & 360 & 165 & 2.45 & 7.66 \\
\hline 5 & 250 & 140 & 2.80 & 8.47 \\
\hline 6 & 342 & 220 & 2.06 & 6.42 \\
\hline 7 & 395 & 250 & 1.98 & 4.82 \\
\hline 8 & 298 & 215 & 3.10 & 7.15 \\
\hline Weight $=\mathrm{W}_{\mathrm{i}}$ & 0.23 & 0.28 & 0.27 & 0.21 \\
\hline $\begin{array}{c}\text { Total }= \\
\sum(\mathrm{W} 1 \text { to } \mathrm{W} 8)\end{array}$ & 2585 & 1540 & 20.56 & 59.60 \\
\hline
\end{tabular}

Table III shows the normalized decision matrix of the experimental test. The normalized decision matrix was obtained using Eq (1).
TABLE III: NORMALIZED DECISION MATRIX

\begin{tabular}{ccccc}
\hline \multirow{2}{*}{$\begin{array}{c}\text { Weldment } \\
\text { W }\end{array}$} & $\begin{array}{c}\text { UTS } \\
(\mathrm{MPa})\end{array}$ & $\begin{array}{c}\text { CVN } \\
(\mathrm{J})\end{array}$ & $\begin{array}{c}\text { BH } \\
(\mathrm{mm})\end{array}$ & $\begin{array}{c}\text { BW } \\
(\mathrm{mm})\end{array}$ \\
\cline { 2 - 5 } & 0.1315 & 0.1364 & 0.1274 & 0.0839 \\
1 & 0.1044 & 0.1234 & 0.1192 & 0.1634 \\
2 & 0.1277 & 0.0974 & 0.1508 & 0.1735 \\
4 & 0.1393 & 0.1071 & 0.1192 & 0.1285 \\
5 & 0.0967 & 0.0909 & 0.1362 & 0.1421 \\
6 & 0.1323 & 0.1429 & 0.1002 & 0.01077 \\
7 & 0.1528 & 0.1623 & 0.0963 & 0.0809 \\
8 & 0.1153 & 0.1396 & 0.1508 & 0.1200 \\
\hline
\end{tabular}

Table IV shows the weighted normalized decision matrix of the experimental test. The weighted normalized decision matrix was obtained using Eq. (2).

TABLE IV: WEIGHTED NORMALIZED DECISION MATRIX

\begin{tabular}{|c|c|c|c|c|}
\hline \multirow{3}{*}{$\begin{array}{c}\text { Weldment } \\
\text { W }\end{array}$} & \multicolumn{4}{|c|}{ Mechanical Property } \\
\hline & \multicolumn{2}{|c|}{ Maximum } & \multicolumn{2}{|c|}{ Minimum } \\
\hline & $\begin{array}{c}\text { UTS } \\
(\mathrm{MPa})\end{array}$ & $\begin{array}{c}\text { CVN } \\
(\mathrm{J})\end{array}$ & $\begin{array}{c}\mathrm{BH} \\
(\mathrm{mm})\end{array}$ & $\begin{array}{c}\mathrm{BW} \\
(\mathrm{mm})\end{array}$ \\
\hline 1 & 0.0302 & 0.0382 & 0.0344 & 0.0176 \\
\hline 2 & 0.0240 & 0.0346 & 0.0322 & 0.0343 \\
\hline 3 & 0.0294 & 0.0273 & 0.0407 & 0.0364 \\
\hline 4 & 0.0320 & 0.0300 & 0.0322 & 0.0270 \\
\hline 5 & 0.0222 & 0.0255 & 0.0368 & 0.0298 \\
\hline 6 & 0.0304 & 0.0400 & 0.0271 & 0.0226 \\
\hline 7 & 0.0351 & 0.0454 & 0.0260 & 0.0170 \\
\hline 8 & 0.0265 & 0.0391 & 0.0407 & 0.0252 \\
\hline
\end{tabular}

The next step was to determine the relative significances or priorities of each alternative $\left(\mathrm{Q}_{\mathrm{i}}\right)$.

For Weldment, W1:

$\mathrm{S}_{\mathrm{w} 1}+1=\Sigma \max$ (weighted normalized decision matrix in Table III)

$$
=0.0684
$$

$\mathrm{S}_{\mathrm{i}-1}=\Sigma \min$ (weighted normalized decision matrix)

$\mathrm{S}_{\mathrm{w} 1-1}=0.0520 ; \frac{1}{S w 1-1}=19.2308$

$\mathrm{S}_{\mathrm{w} 2-1}=0.0665 ; \frac{1}{S w 2-1}=15.0376$

$\mathrm{S}_{\mathrm{w} 3-1}=0.0771 ; \frac{1}{S w 3-1}=12.9702$

$\mathrm{S}_{\mathrm{w} 4-1}=0.0592 ; \frac{1}{S w 4-1}=16.8919$

$\mathrm{S}_{\mathrm{w} 5-1}=0.0666 ; \frac{1}{S w 5-1}=15.0150$

$\mathrm{S}_{\mathrm{w6-1}}=0.0497 ; \frac{1}{S w 6-1}=20.1207$

$\mathrm{S}_{\mathrm{w} 7-1}=0.0430 ; \frac{1}{S w 7-1}=23.2558$

$\mathrm{S}_{\mathrm{w} 8-1}=0.0659 ; \frac{1}{S w 8-1}=15.1745$

$\Sigma \mathrm{S}_{\mathrm{wi}-1}=0.4800 \sum\left(\frac{1}{S_{W i-1}}\right)=137.6965$

$\mathrm{Q}_{1}=0.0684+\frac{0.4800}{(0.0520 \times 137.6965)}$

$\mathrm{Q}_{1}=0.1354$ (applying Eq. (7)) 
The degree of utility $\mathrm{U}_{1}=\frac{Q_{i}}{Q_{\max }} \times 100 \%=\frac{0.1354}{0.1616} \times 100 \%=$ $83.79 \%$ (applying Eq. (8)).

The calculation above were done using Eqs(3) and (4); and Eqs (7) and (8). The value of $\mathrm{Q}_{\mathrm{i}}$ and $\mathrm{U}_{\mathrm{i}}$ are tabulated in Table V.

TABLE V: QI AND UI VALUES

\begin{tabular}{cccc}
\hline Weldment, $\mathrm{W}$ & $\mathrm{Q}_{\mathrm{i}}$ & $\mathrm{U}_{\mathrm{i}}(\%)$ & Rank \\
\hline 1 & 0.1354 & 83.79 & 3 \\
2 & 0.1110 & 68.69 & 6 \\
3 & 0.1019 & 63.06 & 7 \\
4 & 0.1209 & 74.81 & 4 \\
5 & 0.1000 & 61.88 & 8 \\
6 & 0.1405 & 86.94 & 2 \\
7 & 0.1616 & 100 & 1 \\
8 & 0.1185 & 73.33 & 5 \\
\hline
\end{tabular}

In the case of ARAS, Table II is revisited, with the optimal performance ratings, $\mathrm{W}_{0}$ for each criterion; for beneficial criterion, maximum values are considered and for nonbeneficial criteria, minimum values are considered as contained in Table VI.

TABLE VI: DECISION MATRIX USING ARAS METHOD

\begin{tabular}{ccccc}
\hline \multirow{2}{*}{$\begin{array}{c}\text { Weldment } \\
\text { W }\end{array}$} & \multicolumn{4}{c}{ Maximum } \\
\cline { 2 - 5 } & UTS & CVN & BH & BW \\
$(\mathrm{MPa})$ & $(\mathrm{J})$ & $(\mathrm{mm})$ & $(\mathrm{mm})$ \\
\hline 0 & 395 & 250 & 1.98 & 4.82 \\
1 & 340 & 210 & 2.62 & 5.00 \\
2 & 270 & 190 & 2.45 & 9.74 \\
3 & 330 & 150 & 3.10 & 10.34 \\
4 & 360 & 165 & 2.45 & 7.66 \\
5 & 250 & 140 & 2.80 & 8.47 \\
6 & 342 & 220 & 2.06 & 6.42 \\
7 & 395 & 250 & 1.98 & 4.82 \\
8 & 298 & 215 & 3.10 & 7.15 \\
\hline
\end{tabular}

Table VII shows the pre-normalized decision matrix.

TABLE VII: PRE-NORMALIZED DECISION MATRIX

\begin{tabular}{ccccc}
\hline & \multicolumn{4}{c}{ Weld-Mechanical properties } \\
\cline { 2 - 5 } Weldment & \multicolumn{3}{c}{ Maximum } & \multicolumn{2}{c}{ Minimum } \\
\cline { 2 - 5 } & UTS & CVN & BH X* $=\frac{1}{x_{i j}}$ & $\begin{array}{c}\mathrm{X}^{*}=\frac{1}{x_{i j}} \\
(\mathrm{~mW})\end{array}$ \\
\hline 0 & 395 & 250 & 0.5051 & 0.2075 \\
1 & 340 & 210 & 0.3817 & 0.2000 \\
2 & 270 & 190 & 0.4082 & 0.1027 \\
3 & 330 & 150 & 0.3226 & 0.0967 \\
4 & 360 & 165 & 0.4082 & 0.1305 \\
5 & 250 & 140 & 0.3571 & 0.1181 \\
6 & 342 & 220 & 0.4854 & 0.1558 \\
7 & 395 & 250 & 0.5051 & 0.2075 \\
8 & 298 & 215 & 0.3226 & 0.1399 \\
Total, & & & & 1.3587 \\
W $_{1}=\mathrm{W}_{0}$ to & 2980 & 1790 & 3.6960 & \\
W $_{8}$ & & & & \\
\hline
\end{tabular}

Table VIII shows the normalized decision matrix.

TABLE VIII: NORMALIZED DECISION MATRIX USING ARAS METHOD

\begin{tabular}{ccccc}
\hline Weldment & \multicolumn{4}{c}{ Mechanical Property } \\
\cline { 2 - 5 } W & UTS $(\mathrm{MPa})$ & CVN $(\mathrm{J})$ & $\mathrm{BH}(\mathrm{mm})$ & $\mathrm{BW}(\mathrm{mm})$ \\
\hline 0 & 0.1326 & 0.1397 & 0.1367 & 0.1527 \\
1 & 0.1141 & 0.1173 & 0.1033 & 0.1472 \\
2 & 0.0906 & 0.1061 & 0.1104 & 0.0756 \\
3 & 0.1107 & 0.0838 & 0.0873 & 0.0712 \\
4 & 0.1208 & 0.0922 & 0.1104 & 0.0961 \\
5 & 0.0839 & 0.0782 & 0.0966 & 0.0869 \\
6 & 0.1148 & 0.1229 & 0.1313 & 0.1147 \\
7 & 0.1326 & 0.1397 & 0.1367 & 0.1527 \\
8 & 0.1000 & 0.1201 & 0.0873 & 0.1030 \\
\hline
\end{tabular}

Table IX shows the weighted normalized decision matrix using ARAS method.

TABLE IX: WEIGHTED NORMALIZED DECISION MATRIX USING ARAS

\begin{tabular}{|c|c|c|c|c|}
\hline \multirow{3}{*}{$\begin{array}{c}\text { Weldment } \\
\text { W }\end{array}$} & \multicolumn{4}{|c|}{$\begin{array}{l}\text { METHOD } \\
\text { Mechanical Property }\end{array}$} \\
\hline & \multicolumn{2}{|c|}{ Maximum } & \multicolumn{2}{|c|}{ Minimum } \\
\hline & $\begin{array}{c}\text { UTS } \\
(\mathrm{MPa})\end{array}$ & $\begin{array}{c}\text { CVN } \\
(J)\end{array}$ & $\begin{array}{c}\mathrm{BH} \\
(\mathrm{mm})\end{array}$ & $\begin{array}{c}\text { BW } \\
(\mathrm{mm})\end{array}$ \\
\hline 0 & 0.0305 & 0.0391 & 0.0369 & 0.0321 \\
\hline 1 & 0.0262 & 0.0328 & 0.0279 & 0.0309 \\
\hline 2 & 0.0208 & 0.0297 & 0.0298 & 0.0159 \\
\hline 3 & 0.0255 & 0.0235 & 0.0236 & 0.0150 \\
\hline 4 & 0.0278 & 0.0258 & 0.0298 & 0.0202 \\
\hline 5 & 0.0193 & 0.0219 & 0.0261 & 0.0182 \\
\hline 6 & 0.0264 & 0.0344 & 0.0355 & 0.0241 \\
\hline 7 & 0.0305 & 0.0391 & 0.0369 & 0.03321 \\
\hline 8 & 0.0230 & 0.0336 & 0.0236 & 0.0217 \\
\hline
\end{tabular}

Table $\mathrm{X}$ shows the $\mathrm{S}_{\mathrm{i}}$ and $\mathrm{U}_{\mathrm{i}}$ Values using ARAS method. TABLE X: Si AND UI VALUES USING ARAS METHOD

\begin{tabular}{cccc}
\hline $\begin{array}{c}\text { Weldment } \\
\mathrm{W}\end{array}$ & $\mathrm{S}_{\mathrm{i}}$ & $\mathrm{U}_{\mathrm{i}}=\frac{\mathrm{Si}}{\mathrm{W} 0} \times 100 \%$ & Rank \\
\hline 0 & 0.1386 & 100.0000 & - \\
1 & 01178 & 84.9928 & 3 \\
2 & 0.0962 & 69.4084 & 6 \\
3 & 0.0876 & 63.2035 & 7 \\
4 & 0.1036 & 74.7475 & 4 \\
5 & 0.0855 & 61.6883 & 8 \\
6 & 0.1204 & 86.8687 & 2 \\
7 & 0.1386 & 100.0000 & 1 \\
8 & 0.1019 & 73.5209 & 5 \\
\hline
\end{tabular}

\section{B. Discussion of Results}

This study was made in two parts, application of COPRAS for the determination of the optimum weld properties. The process is explained as follows; Table II shows the results of the weld mechanical properties obtained from tensile and impact strength tests conducted, as well as the measurements of the bisected weld geometry to obtain the bead height $(\mathrm{BH})$ and bead width (BW) respectively. Table II also contains the weight of each of the weld properties.

Table III shows the normalized value of the experimental test results. Normalization process is a reduction process that further simplifies the test result values. The value lies between 0 and 1. Table IV shows the weighted normalized values of each of the results of each of the weld property and their corresponding weights. These values also lie between 0 and 1.

The relative significances and properties of each alternative as well as the degree of utility were determined and shown in Table V. The degree of utility was used as the criteria for ranking the weld quality properties. In this study weldment 7 was found to possess the best weld properties with UTS of $395 \mathrm{MPa}, \mathrm{CVN}$ of $250 \mathrm{~J}, \mathrm{BH}$ of $1.98 \mathrm{~mm}$ and BW of $4.82 \mathrm{~mm}$.

The second part deals with using ARAS in determining the optimum weld properties. The application of ARAS starts with the content in Table VI, which contains the mechanical properties of the weldments. Table VII shows the prenormalization process subjected under the larger the value of the weld properties, the better the quality which is the referred to as maximum and the lower the values of the weld properties, the better the quality which is referred to as minimum. 
Table VIII shows the normalized values of the test results of the weld properties, these values normally lie between 0 and 1. Table IX shows the weighted normalized value of the weld properties. Table $\mathrm{X}$ shows the optimality function and the utility degree comprising of each of the mechanical properties shown in Table IX. The utility degree was again used as the criteria for ranking the weldment. In this study weldment 7 was ranked as the weldment with the best mechanical properties.

From this study the application of COPRAS and ARAS methods showed that weldment 7 has the best quality properties.

\section{CONCLUSION}

In this study, the COPRAS - ARAS methods were used to select the optimum welding process parameters. The procedure involves the conduction of the welding operations according to the set out experimental matrix design and the mechanical properties of the weldments obtained. The assessment of the results of these mechanical properties by Experts were converted to weights which were used for the optimization process. Eventually, the optimized process parameters shows that weldment 7 has the best mechanical properties which were in line with the criteria for categorizing weld properties.

\section{REFERENCES}

[1] C.E. Etin-Osa, J. I. Achebo and K. O. Obahiagbon. (2020). Design and Fabrication of Portable Weld Residual Stress Measuring Device using MBN Principle. NIPES Journal of Science and Technology Research 2(3) pp. 70-84

[2] Boumerzoug, Z., Derfouf, C. and Baudin, T. (2010). Effects of welding on microstructure and Mechanical Properties of an industrial Low carbon steel, Engineering, 2, 502-506.

[3] Aytaç adali, E. \& Tusisik, A. (2016). Air conditioner selection problem with COPRAS and ARAS methods. Manas Journal of Social Studies, 5(2), 124-138.

[4] Andruskevicius (2005) evaluated some contractors using COPRAS, A. (2005). Evaluation of contractors by using COPRAS - the multiple criteria method. Technological and Economic Development of Economy, 11(3), 158-169.

[5] Balezentiene, L., \& Kusta, A. (2012). Reducing greenhouse gas emissions in grassland ecosystems of the central Lithuania: multicriteria evaluation on a basis of the ARAS method. The \&ientfic World Journal, 1-11.

[6] Chatterjee, P. \& Chakraborty, S. (2014). Flexible manufacturing system selection using preference ranking methods: A comparative study, International Journal of Industrial Engineering Computations, 5, 315-338.

[7] Kaklauskas, A., Zavadskas, E.K., Raslanas, S., Ginevicius, R., Komka, A., \& Malinauskas, P. (2006). Selection of low e-windows in retrofit of public buildings by applying multiple criteria method COPRAS: A Lithuanian case. Energy and Buildings, 38(5), 454-462.

[8] Saaty, T.L. (1987). The analytic hierarchy process-what it isand how it is used. McGraw-Hill, New York, 9(3), 161-176.

[9] Dadelo, S., Turskis, Z., Zavadskas, E. K., \& Dadeliene, R. (2012). Multiple criteria assessment of elite security personal on the basis of ARAS and expert methods. Economic Computation and Economic Cybernetics Studies and Research, 46(4), 65-87. 